\title{
The Role of Alcohol
} Involvement in Fatal Dedestrian Collisions

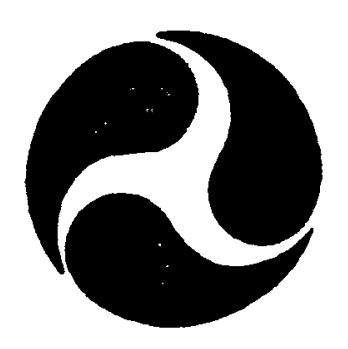

National Center for Statistics and Analysis National Highway Traffic Safety Administratio

Twenty-Ninth Annual Conference AMERICAN ASSOCIATION FOR AUTOMOTIVE MEDICINE 
The Role of Alcohol Involvement

in Fatal Pedestrian Collisions

James C. Fell and B. Grace Hazzard*

National Highway Traffic Safety Administration Washington, D. C.

\section{ABSTRACT}

Although pedestrians are involved in only 2 percent of all traffic crashes, they are 16 percent of all traffic fatalities in the United States. Data from the Fatal Accident Reporting System (FARS) for 1984 indicate that pedestrian fatalities have decreased 7 percent since 1975 with the greatest decrease in child (under age 14) fatalities $(-42 \%)$. Pedestrian fatality rates per 100,000 population are lowest for children under 14 and highest for people 65 or older. For pedestrians aged 14-64, the rates have not changed over the past 10 years. Alcohol involvement is most prevalent in this age group.

Data indicate that $40 \%$ of adult pedestrians (over age 14) are intoxicated at the time of their death. Three out of five of the fatally injured pedestrians who are intoxicated are at very high blood alcohol levels (BACs $\geq .20 \%$ ).

Intoxicated pedestrians are more likely to be male, aged 25 to 64 and involved in a fatal accident between 12 midnight and $6 \mathrm{AM}$, on a rural roadway, away from an intersection, with the striking vehicle being a passenger car, light truck or a hit and run vehicle.

A total of 2500 intoxicated adult pedestrians continue to be killed each year with very little change since 1975. Available countermeasures for possible consideration include dram shop laws applied to pedestrian victims and technology transfer of new, innovative ideas that have worked to reduce child pedestrian fatalities.

*The opinions expressed in this paper are those of the authors and not necessarily those of the National Highway Traffic Safety Administration. 
IN 1984 IN THE UNITED STATES, 7022 pedestrians were killed in motor vehicle accidents out of a total of 44,241 total traffic fatalities [1]*. In 1983 an estimated 140,000 police reported pedestrian collisions occurred with at least $117,000(84 \%)$ resulting in some injury [2]. The number of pedestrian involvements in all police reported accidents in 1983 was only $2 \%$. However, pedestrians accounted for 16 percent of ali traffic fatalities in 1983.

Pedestrian fatalities have been consistently accounting for 16-18 percent of traffic fatalities throughout the 1970's and 80 's. But this is down from earlier decades in the U. S. In 1933, for example, there were 12,840 pedestrian deaths or 41 percent of the total traffic fataljties [3]. By 1946 pedestrian deaths dropped to $34 \%$ of all fatalities. In 1952 the proportion was $24 \%$ and by 1965 the proportion leveled off at $18 \%$.

There were even more striking reductions over these years in pedestrian fatality rates. For example, in 1936 there were 6.05 pedestrian fatalities for every $100 \mathrm{million}$ vehicle miles traveled (VMT). By 1983, there were only 0.41 pedestrian fatalities per 100 million UMT, a remarkable 14-fold decrease.

Among the various reasons reported for these substantial reductions were such factors as the development of Jimited access highwavs, improved traffic controls, and construction of separate pedestrian walkways (sidewalks) [3]. Considering that rates have leveled off since 1965, it is questionable whether significant reductions can occur without substantially new efforts in pedestrian safety.

It has been known for some time that alcohol plays a major role in fatal traffic accidents in the U.S., including pedestrian fatalities [4]. The purpose of this analysis is to estimate the magnitude of the alcohol involvement problem in pedestrian fatalities and, to the extent possible, determine the apparent role alcohol plays in these accidents.

Fell/Hazzard

* Numbers in brackets indicate References listed at the end of the paper. 
METHOD

The Fatal Accident Reporting System (FARS) files provided information on alcohol levels in drivers and pedestrians [5]. FARS has been in existence since 1975. It contains standard data on a census of motor vehicle accidents in the U.S and Puerto Rico that result in a fatality within 30 days. Each accident case has upwards of 90 different coded data elements that characterize the accident, the vehicles and the people involved. These data are gathered by State employees under contract to the National Highway Traffic Safety Administration (NHTSA) from the State's own source documents. These generally include some or all of the following:

- Police Accident Reports

- State Vehicle Registration Files

- State Friver Licensing Files

- State Highway Depar tment Data

- Vital Statistics

- Death Certificates

- Coroners/Medical Examiners Peports

- Hospital Medical Records

- Emergency Medical Services Reports

Alcohol involvement in FARS is reported in three different data elements:

(1) Results of official tests of a driver or pedestrian for blood alcohol content (BAC). This is considered the most reliable indicator of alcohol involvement.

(2) Police reported alcohol involvement. This is coded "yes" for a drjver or pedestrian if the police indicate so on their police accident report.

(3) Violations charged to the driver. If a driver was charged with driving while intoxicated (INI), driving under the influence of liquor (DUIL) or some other alcohol related offense, this is coded and can be used as an alcohol involvement indicator for the drivers.

For the purposes of this research, the results of blood alcohol concentration (BAC) tests on fatally injured adult pedestrjans (age 14 or older) in a 15 State sample were used to generate national estimates. Only "adult" (age 14 or older) pedestrians were selected for alcohol analyses since medical examiners and coroners do not routinely test children under the age of 1.4. The 15 States were 
selected because they have consistently tested and reported BAC results on over $80 \%$ of the fatajly in jured adult pedestrians and drivers in their State since 1980. Testing in other States ranges anywhere from 28 to $70 \%$ of the adult pedestrians. Since there could have been a selection bias for testing in the States with lower testing rates, they were excluded from the analysis. The representativeness of this 15 State sample regarding key highway safety criteria has been reported elsewhere [6]. National estimates of the number of intoxicated adult pedestrian fatalities are made by applying the percentages found in the 15 States sample.

A fatally injured pedestrian was considered intoxicated if the RAC was greater than or equal to $.10 \%$ at the time of death (assuming the death occurred or the blood sample was taken within 4 hours of the crash).

Since most drivers involved in fatal pedestrian collisions survived, very few were routinely tested for alcohol. Therefore, driver alcohol involvement in FARS pedestrian accidents was determined by examining the "police reported alcohol involvement" variable and the "violations charged" variable in addition to a BAC result, if a test was given.

The National Accident Sampling System (NASS) was also examined to determine the number of pedestrians injured per year in motor vehicle accidents. Fstablished in 1979, NASS contains data from full investigations of a statistical sample of police reported motor vehicle crashes of all types and severities. About 10,000 accidents per year are investigated by 50 research teams around the country. Fach accident case contains over 300 data elements. National estimates are then made concerning the distribution and severity of the 7 million accidents reported each year to police in the U.S. The NASS data files were used to estimate the number of pedestrian accident involvements and the number of injured pedestrians each year [2]. 
Table 2

Pedestrian Fatalities Per 100,000 Population

in the U.S.

1975-1984

Year

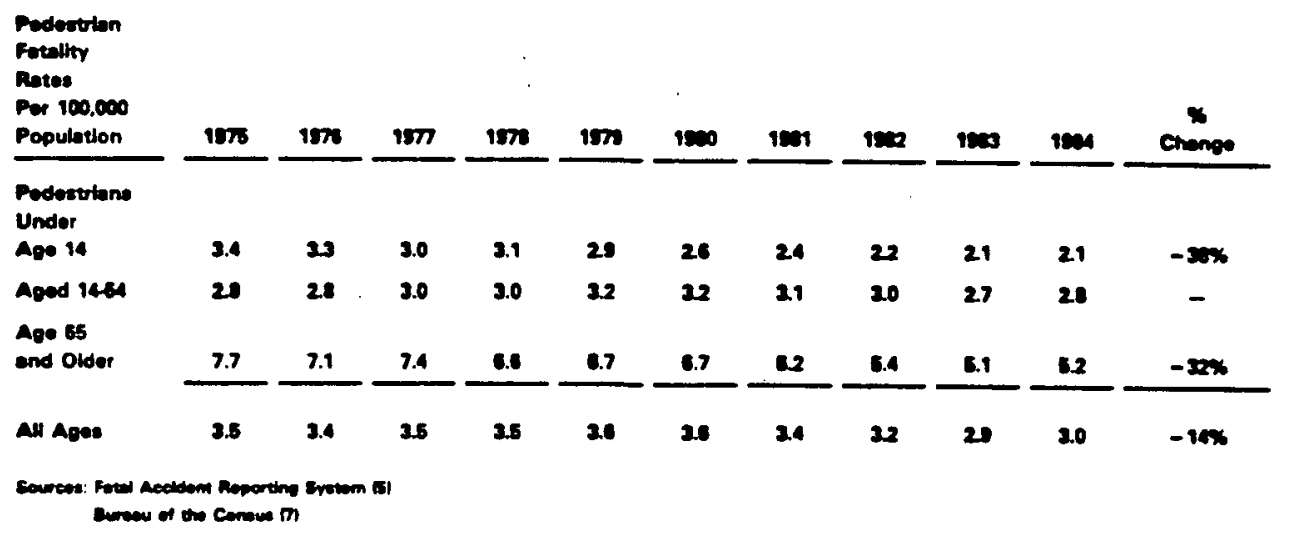

Annual pedestrian fatalities aged 14-64 have increased since $1975(+12 \%)$, but the rate per 100,000 population has stayed the same. The highest pedestrian fatality rate is in the 65 and older group. The rate per 100,000 population has been consistently 2 to 3 times higher than for the other age groups. But the number of fatalities among pedestrians over age 65 has decreased 168 since 1975 while the rate per 100,000 population has decreased $32 \%$.

Between 1975 and 1979, children (under age 14) accounted for about $20 \%$ of all pedestrian fatalities. Since 1980, child pedestrian fatalities were only 158 of the total.

Table 3 shows estimates of pedestrian accident involvements based upon the NASS data. These estimates, even though combined for 1979-80 and for 1981-83, are still subject to an error of at least $+20 \%$. The injury rates per 100,000 population are substantially different than the fatality rates. The highest injury rate is for children under 14 . At half those rates are the 14-64 year olds. The over 65 year olds have the lowest injury rates. 


\section{Table 3}

Injured Pedestrians in the U.S.

Years
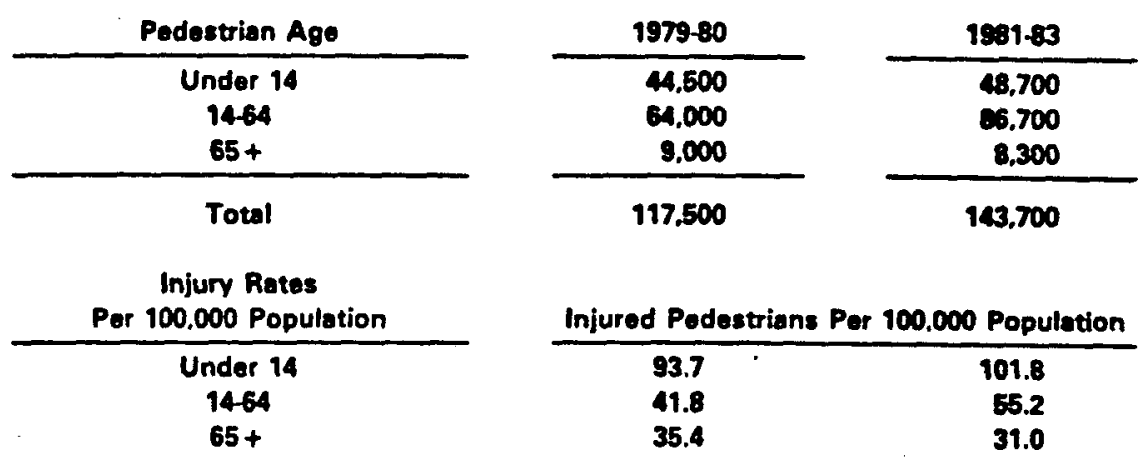

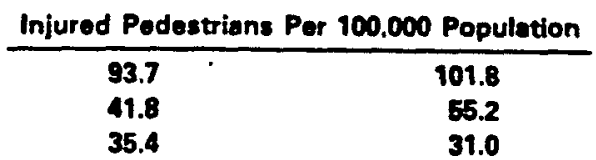

Sources: National Aceddom sampling Syetem [2] Cureas of the Consus (7)

Most of these differences can be explained by the differences in tolerance to trauma for children and younger people compared to people 65 or older. Given the same crash conditions, a person 65 or older has a greater risk of dying than a child under the age of 14. So, persons aged 65 and older are not involved in a high number of pedestrian accidents per capita, but when they are, the chances of fatality are much greater than younger persons.

The sex of the pedestrjan also plays a major role. Table 4 shows that since 1975, males accounted for $70 \%$ of the pedestrian fatalities. This differs somewhat within the three age groups, but males are still overrepresented in each group. For pedestrians under the age of 14 , males account for about $65 \%$ of the fatalities; for aged 14-64, males account for 75\%; and for 65 and older, males are about 608 of the fatalities.

Pedestrian fatalities are a major highway loss among people aged 65 and older and for males between the ages of 14 and 64 . 
Table 4

Percent of Pedestrian Fatalities That

Are Male/Female by Pedestrian Age

\begin{tabular}{|c|c|c|c|c|c|c|c|c|c|c|}
\hline $\begin{array}{l}\text { Age of } \\
\text { Pedestrien Fotality }\end{array}$ & 1975 & 1976 & 1977 & 1978 & 1979 & 1890 & 1รง1 & 1 ex & $\operatorname{Imas}$ & Is94 \\
\hline $\begin{array}{l}\text { Under Age } 14 \\
\text { Percent Male } \\
\text { Porcent Fomole }\end{array}$ & $\frac{\cos x}{37 \%}$ & $\mathbf{3}$ & $\mathbf{q}$ & 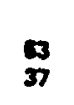 & $\mathbf{3 7}$ & $\mathbf{3}$ & $\mathbf{x}$ & 20 & 35 & $\begin{array}{l}63 \\
\mathbf{3 7}\end{array}$ \\
\hline $\begin{array}{l}\text { Aged 1464 } \\
\text { Male } \\
\text { Fomale }\end{array}$ & $\begin{array}{l}70 \% \\
25 \%\end{array}$ & $\begin{array}{l}74 \\
20\end{array}$ & $\begin{array}{l}74 \\
26\end{array}$ & $\begin{array}{c}\boldsymbol{7} \\
\mathbf{w}\end{array}$ & $\frac{75}{25}$ & $\begin{array}{r}74 \\
26 \\
\end{array}$ & $\frac{\pi}{25}$ & $\begin{array}{l}74 \\
26\end{array}$ & $\begin{array}{l}\pi \\
25\end{array}$ & $\begin{array}{l}7 \\
23\end{array}$ \\
\hline $\begin{array}{l}\text { Aged es and Oider } \\
\text { Mole } \\
\text { Famble }\end{array}$ & $\begin{array}{l}62 \% \\
30 \%\end{array}$ & $\begin{array}{l}\mathbf{6 3} \\
37\end{array}$ & 62 & 35 & 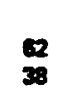 & 3 & $\infty 0$ & 2 & $\begin{array}{l}8 \\
42\end{array}$ & 81 \\
\hline $\begin{array}{l}\text { All Ages } \\
\text { Malo } \\
\text { Famale }\end{array}$ & $\begin{array}{l}69 \% \\
31 \%\end{array}$ & $\begin{array}{l}69 \\
31\end{array}$ & $\begin{array}{l}69 \\
31\end{array}$ & $\begin{array}{l}71 \\
29\end{array}$ & $\begin{array}{l}\mathbf{7 0} \\
\mathbf{3 0}\end{array}$ & $\begin{array}{l}70 \\
30\end{array}$ & $\begin{array}{l}n \\
30\end{array}$ & $\mathbf{7 0}$ & $\begin{array}{l}70 \\
30\end{array}$ & $\begin{array}{l}71 \\
20\end{array}$ \\
\hline
\end{tabular}

Source: Fotal Aceldent Roporting Sretem (s)

\section{ALCOHOL}

Table 5 shows the percent of adult pedestrian fatalities who were intoxicated at the time of their death for the years 1980-1984. About 40\% of the adult pedestrians were drunk and this percentage did not vary much over the 5 year period.

The three adult age groups, however, did differ regarding the proportion who were drunk. The proportion of younger (aged 14-24) adult pedestrians who were drunk was slightly less than pedestrians aged 25-64. The older pedestrians (age 65+) were consistently and significantly lower in the proportion drunk, showing rates of about 1 out of 8 each year. Figure 1 shows the alcohol involvement in even finer age groups for the year 1983. We estimate, based upon the percentages in the 15 State sample, that approximately 2500 adult pedestrians killed in crashes each year since 1980 were intoxicated. 
Table 5

Percent of Adult Pedestrian Fatalities

Who Were Intoxicated at the Time of the Collision

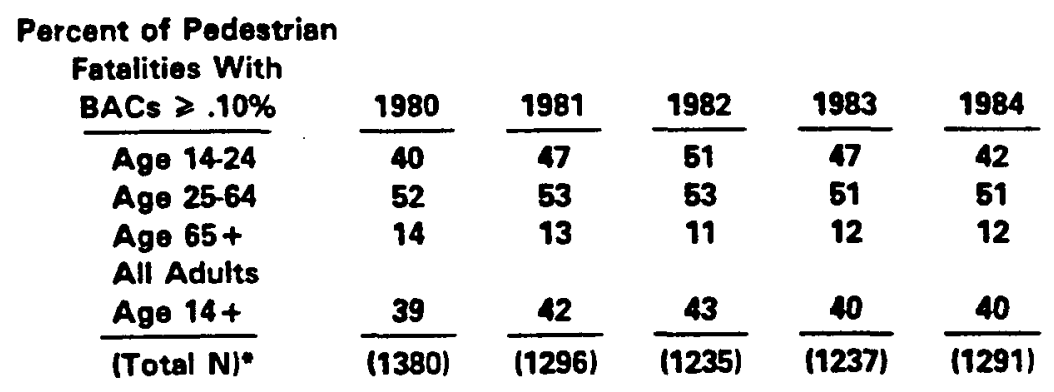

Source: Fatal Accident Reporting System (1980-1984)

15 Good Reporting States

- Adult Pedestrians Tested for Alcohol and Result Known (N)

Figure 1

FARS 1983

Pedestrian Fatalities With Known

Alcohol Test Results by Age

(15 States)

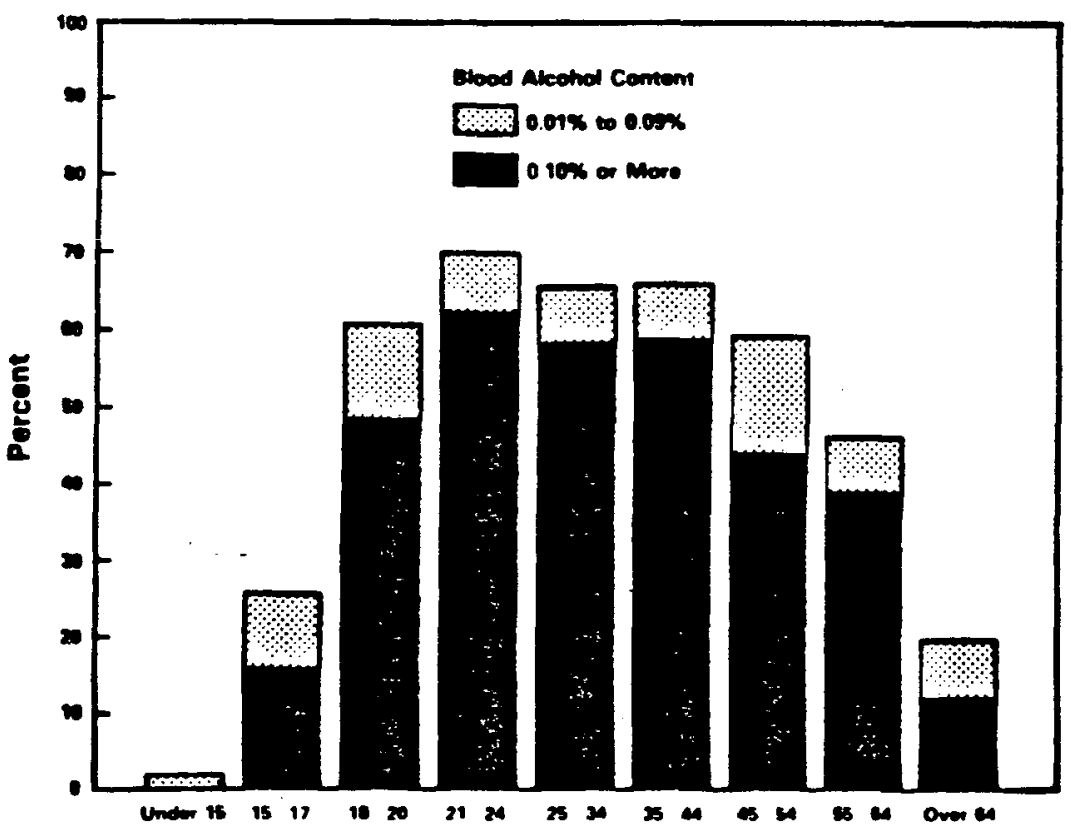

Fell/Hazzard 
Alcohol abuse is clearly a major contributor to pedestrian fatalities. Table 6 shows the percent of adult pedestrian fatalities who were at BACs of $.20 \%$ or greater for 1980-1984 and the average BAC of the positive alcohol involved pedestrians. (Most researchers would agree that BAC levels of $.20 \%$ or greater are definite indicators of alcohol abuse or problem drinking.) Sixty percent of the intoxicated pedestrians who were killed were alcohol abusers. Some were so intoxicated that they may not have known where they were or whether they were even on a highway.

The average BAC of all pedestrians with any positive alcohol was very close to $.20 \%$ with many in the $.30 \%$ to $.40 \%$ percent range. This contrasts with the average BAC of about .16\% for fatally injured drivers with any positive blood alcoho]. [8].

\section{Table 6}

Percent of Adult Pedestrian Fatalitios

At BACs $\geqslant 20 \%$

\begin{tabular}{|c|c|c|c|c|c|}
\hline \multirow[b]{2}{*}{$\begin{array}{l}\text { Percent of Adult Pedestrians Killed } \\
\text { With BACs }>20 \%\end{array}$} & 1980 & 1981 & 1982 & 1983 & 1984 \\
\hline & 24 & 25 & 26 & 24 & 25 \\
\hline $\begin{array}{l}\text { Percent of Alcohol Positives } \\
\text { (BAC }>.01) \text { With BAC } \geqslant .20 \%\end{array}$ & 49 & 50 & 51 & 49 & 52 \\
\hline $\begin{array}{l}\text { Percent of Intoxicated (BAC }>.10) \\
\text { Pedestrian Fatalities With } \\
\text { BACs }>20 \%\end{array}$ & 60 & 60 & 60 & 60 & 63 \\
\hline Averege BAC of Alcohol Positives & .188 & 195 & .198 & .193 & .199 \\
\hline \multicolumn{6}{|l|}{$\begin{array}{l}\text { Source: Fatal Accident Reporting Systom } \\
15 \text { Good Roporting States }\end{array}$} \\
\hline $\begin{array}{l}\text { CHARACTFRISTICS OF FATAI. } \\
\text { PEDESTRIANS }\end{array}$ & ACCII & ENTS & INVOLI & JNG & IRUNK \\
\hline
\end{tabular}

There are a number of differences in the characteristics of accidents in wich intoxicated versus sober adult pedestrians are killed.

- More than twice the proportion of adult male pedestrian fatalities were intoxicated as compared to adult female fatalities (48\% vs 23\%). Males account for $70 \%$ of the adult pedestrian fatalities but $83 \%$ of the intoxicated pedestrians. (Table 7) 
- As expected, a greater percent of the pedestrian fatalities that occurred between midnight and 6 AM were intoxicated than at any other time - 67\%. Forty-four percent of the fatalities between 6 PM and midnight were intoxicated while only $8 \%$ of those occurring between $6 \mathrm{AM}$ and noon were drunk. (Table 7 )

\section{Table 7 \\ Percent Intoxicated Adult Pedestrian \\ Fatalities as a Function of Accident Situation \\ 1983}

\begin{tabular}{lc} 
Accident Situation & $\begin{array}{c}\text { Percent Adult Pedestrian } \\
\text { Fatalities With BACs } \geqslant .10 \%\end{array}$ \\
\cline { 2 - 2 } Pedestrian Sex: & \\
Male & $48 \%$ \\
Female & $23 \%$ \\
Time of Day: & \\
$12 \mathrm{am}-6 \mathrm{am}$ & $67 \%$ \\
$6 \mathrm{am} \cdot 12 \mathrm{pm}$ & $8 \%$ \\
$12 \mathrm{pm} \cdot 6 \mathrm{pm}$ & $13 \%$ \\
$6 \mathrm{pm}-12 \mathrm{am}$ & $45 \%$
\end{tabular}

- A greater proportion of the pedestrians killed in rural areas were drunk compared to urban areas (56\% vs 35\%). Also, $18 \%$ of the sober pedestrians $(B A C=0)$ were killed in rural areas while $37 \%$ of the intoxicated pedestrians were killer in rural areas. (Table 8)

- Over $90 \%$ of the pedestrians were struck on the roadway. However, $43 \xi$ of the pedestrians struck on the roadway were intoxicated whereas only $20 \%$ of the pedestrians struck off the roadway were drunk. Fourteen percent of the sober pedestrians were struck off the roadway while only 5\% of the intoxicated pedestrians were struck off the roadway. (Table 8) 
- While $29 \%$ of the pedestrians struck at an intersection were intoxicated, $44 \%$ of the pedestrians struck away from an intersection were drunk. Twenty-eight percent of the sobers were struck at an intersection; $16 \%$ of the intoxicated pedestrians were struck at an intersection. (Table 8)

\section{Table 8}

\section{Accident Situation}

Accident Location:

Urban

$35 \%$

Rural

$56 \%$

On Roadway

$43 \%$

Off Roadway

$20 \%$

At Intersection

$29 \%$

\section{Away From}

Intersection

$44 \%$

Most pedestrians were struck by autos, light trucks and vans, and about $40 \%$ of them were intoxicated. A fewer percent struck by medium or heavy trucks were drunk (27\%) and a very small percent struck by motorcycles were drunk ( $8 \%)$. However, an interesting finding was that $56 \%$ of the pedestrians killed by "other vehicles" were intoxicated . Most of the "other vehicles" that killed pedestrians were hit and rum (78\%) and on/off road vehicles (12\%). However, $86 \%$ of the other vehicles that struck and killed intoxicated pedestrians were hit and run. (Table 9)

- Finally, the vehicle maneuver just prior to striking the pedestrian was examinet. The vehicle was going straight $79 \%$ of the time when a sober pedestrian was struck compared to $87 \%$ of the time for intoxicated pedestrians. In 58 of the sober cases the vehicle was turning compared to 18 of the intoxicated cases. In 58 of the sober cases the vehicle was passing or changing lanes compared to only 28 of the intoxicated cases. (Table 9) 


\section{Table 9}

\begin{tabular}{|c|c|}
\hline Accident Situation & $\begin{array}{l}\text { Percent Adult Pedestrian } \\
\text { Fatalities With BACs } \geqslant .10 \%\end{array}$ \\
\hline $\begin{array}{l}\text { Striking Vehicle: } \\
\text { Auto } \\
\text { Lt Truck/Van } \\
\text { Med/Heavy Truck } \\
\text { Motorcycle } \\
\text { Other Vehicle }\end{array}$ & $\begin{array}{r}39 \% \\
43 \% \\
27 \% \\
8 \% \\
56 \%\end{array}$ \\
\hline $\begin{array}{l}\text { Vehicle Maneuver: } \\
\text { Straight } \\
\text { Turning } \\
\text { Passing or Changing } \\
\text { Lanes } \\
\text { Other }\end{array}$ & $\begin{array}{l}42 \% \\
13 \% \\
27 \% \\
39 \%\end{array}$ \\
\hline
\end{tabular}

There were apparent seasonal variations with respect to the proportion of pedestrians intoxicated ranging from $35 \%$ in the winter to $48 \%$ in the summer manths. (Table 10)

Driver age and the driver's prior convictions were examined to see if drivers who struck sober pedestrians were different from drivers who struck intoxicated ones. No differences were found (Table 10). Fifty-six percent of the pedestrians struck by drivers of unknown age were intoxicated. This may reflect the incidence of hit and run accidents which occurrer later at night under conditions where the probability of the pedestrian and driver being drunk were highest.

Table 10

\begin{tabular}{l} 
Accident Situstion \\
\hline Season: \\
Winter \\
Spring \\
Summer \\
Fall \\
Driver's Age: \\
15-24 \\
$25-64$ \\
65 and Older \\
Unknown \\
Driver's Prior Convictions: \\
None \\
One or More \\
Source for Tables 7.10:
\end{tabular}

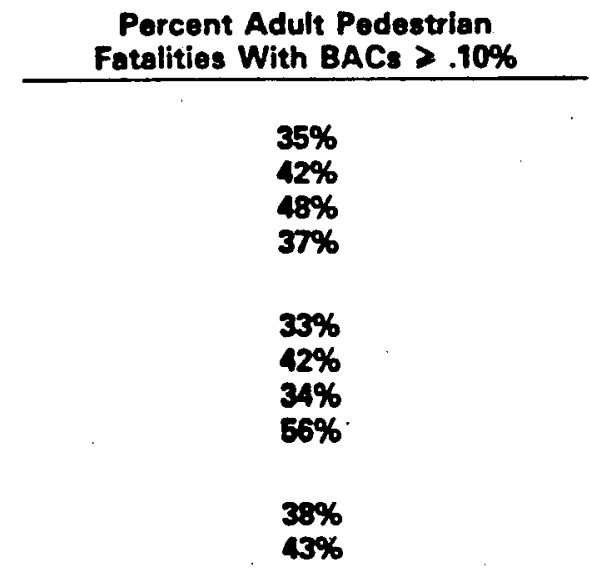

Fatal Accident Reporting System 1983 15 States
Fel1/Hazzard 
The percent of drivers who struck and killed pedestrians and were drinking prior to the crash appears in Table 11. As indicated, this has remained at about 208 over the periot from 1980 to 1984.

However, it does differ according to the age of the pedestrian killed. on the average over the five year period only 11 of the drivers that struck pedestrians aged 13 and under were drinking; 258 who struck pedestrians aged 14-64 were drinking;

and $10 \%$ of the drivers who struck 65 or older pedestrians were drunk. This probably reflects the time of day when the fatal collisions occurred.

Table 12 also indicates the percent of fatal adult pedestrian accidents with any alcohol involvement; that is, the percent where either the pedestrian or driver or both were drinking. This has remained at 53-56\% throughout 1980-84.

\section{Table 11}

Percent of Drivers Who Were Drinking By Age of Pedestrian Killed 1980-1984

Age of

Pedestrian

Percent Drivers Drinking

Fatality

Under Age 14

Age 14-64

$\begin{array}{llll}1980 & \frac{1981}{14} & \frac{1982}{10} & \frac{1983}{8}\end{array} \frac{1984}{15}$

Age 65 and Older

$\begin{array}{lllll}27 & 29 & 24 & 24 & 20\end{array}$

All Ages

$\begin{array}{lll}10 & 11 & 12 \\ 21 & 22 & 20\end{array}$

99

Source: FARS 1980-1984

15 States 


\title{
Table 12
}

\section{Percent of Fatal Adult \\ Pedestrian Accidents With Alcohol Involvement \\ 1980.1984}

\author{
Percent of Fatal \\ Adult Pedestrian \\ Accidents Where \\ Either the Pedestrian, \\ the Driver, or Both \\ Had Been Drinking
}

1980

198

$1982 \quad 1983$

1984

Source: FARS 1980-1984

15 States

\section{DISCUSSION}

From basic statistics the pedestrian accident problem can be summarized as follows:

- Although accidents involving pedestrians are a small proportion of all accidents (2\%) they are a relatively large part of the traffic fatalities (16\%). Also, when a pedestrian is struck by a motor vehicle the risk of injury and death is much greater than for any other traffic accident victim (vehicle occupants, pedalcyclists, motorcyclists included).

- The rate of pedestrian fatalities per 100,000 population is very high for persons age 65 or older and relatively low for those 14-64 and lowest for children under 14. The opposite is true for surviving injured pedestrians with children under 14 having rates twice that of older people.

- Males are very much overtepresented in pedestrian fatalities for every age group including children under age 14. Cverall, males consistently account for 708 of the pedestrian fatalities.

Fell/Hazzard 
- Fatalities among pedestrians under age 14 used to account for 20 s of the total pedestrian fatalities (fron 1975-1979). Since 1980, that proportion has dropped to 158 The rate of pedestrian fatalities under age 14 per 100,000 population has dropped $38 \%$ since 1975 (See Table 2). This takes into consideration any population changes that have occurred since 1975.

All of these fatality statistics indicate that perhaps the focus should be on male pedestrians and older pedestrians if any further impact is to be made on the problem. It also indicates that countermeasures for children may be working.

With regard to alcohol involvement, the key findings indicate the following:

- Alcohol involvement is hjghest for pedestrians aged 25-64 with 14-24 year olds very close behind. older pedestrians are not drunk at anywhere near the rates of their younger counterparts. However, they may be similarly impajred by age factors which could account for part of their high fatality rates.

- Most alcohol involver pedestrians are alcohol abusers as indicated by the high BACs found. Apparently the ability to cross a street or negotiate in traffic is not severely affected until pedestrians have BACs well above .10\% [9]. This contrasts with the relative risk of accident involvement for drjvers wich begins to climb significantly at BAC levels of $08-.108$ [4].

The alcohol problem is particularly acute for male adult perlestrians; between 6 pm and 6 am (and especially 12 am - 6 am); in rural areas; for pedestrians on the roadway and/or crossing at non-intersections; for accidents occurring in summer manths; and for pedestrians struck by passenger cars, light trucks, and hit and run vehicles. These factors probably indicate an increased risk of a perlestrian struck and killed when he is walking home late at Fell/Hazzard night on a rural, dark roadway, is severely intoxicated and most likely disor iented. 
- The alcohol problem is not all on the pedestrian's part as indicated by the 15-20\% of the drivers who struck them reported by police as had been drinking. It is probably not unusual for an intoxicated pedestrian to be struck and killed by an intoxicated driver late at night on an unlighter rural road with the pedestrian probably weaving in the roadway and into the drivers path [9]. Reactions on both their parts are slow and a collision results.

- The finding of a high percentage of pedestrians struck by $h i t$ and run drivers being intoxicated is interesting and may indicate that both the driver and pedestrian were intoxicated.

CONCLUSIONS AND RECOMMENDATIONS

Based upon the findings in these analyses, the following can be concluded:

(1) Alcohol involvement in fatal pedestrian collisions is a major highway safety problem that has not changed significantly for several years. Unless something is done or conditions change, a total of 2500 alcohol related pedestrian fatalities per year will continue to occur throughout the rest of the 1980s. Unlike the proportion of driver fatalities who are intoxicated which has gone down from $50 \%$ in 1980 to $43 \%$ in 1984 [1], the proportion of intoxicated adult pedestrian fatalities continues to be around the $40 \%$ level during that period with no signs of any trend (up or down). 
(2) Although there are some salient features of fatal pedestrian accidents involving alcohol (late night, non-intersection, males, severe intoxication, under 65 , etc.), they suggest no easy solutions. Police action to keep intoxicated pedestrians off public roadways may not be practical. Another approach might be to make dram shop laws applicable to intoxicated pedestrians where an alcohol server could be held liable if an obviously intoxicated recepient is injured or killed as a pedestrian. To date, 38 States and the Nistrict of Columbia have dram shop laws. But the majority do not recognize first party liability; that is, they only recognize third party liability where the intoxicated driver injures or kills someone else. A few States, notably Massachusetts, allow the first party (intoxicated person) to recover damages suffered due to his intoxication from the server [10]. This includes intoxicated pedestrians who wander out in to roadways and are struck and killed. It seems reasonable that calling a cab or providing a ride home for an intoxicated patron is as necessary for pedestrians as for drivers. This concept should also be applied to alcohol server training courses to make the server aware that intoxicated pedestrians are a major part of the alcohol/highway safety problem in addition to drivers.

(3) The rate of child fatalities per 100,000 population had a signjficant decrease over the past decade (38\%). Some of this decrease must be due to the improved pedestrian education efforts for children, school bus laws, the ice cream vendor countermeasure [11] and other recent programs aimed toward children. Some of the techniques and innovations of these development efforts should be transferred to the adult problem aimed at both the drinking pedestrians and elderly adult.

In summary, the pedestrian problem in traffic fatalities is significant and for adult pedestrians has not changed in recent years $[12,13]$ (also see Table 1). It deserves more attention. Fncouraging signs with regard to countermeasures are with the decreasing child fatality rates. The discouraging signs are with the alcohol involvement problem and with the elderly. New research or new innovative ideas are needed if we are to make any progress in these areas.

Fell/Hazzard 


\section{ACKNOWLFDGMENTS}

The authors wish to thank Virginia Randall and Louann Hall of the Information Systems Division for their expert data retrieval effort and Carl Nash of the Accident Investigation Division and Alfred Farina of the office of nriver and Pedestrian Research for their important editorial comments. 


\section{REFERBNCES}

1. National Highway Traffic Safety Administration, FATAL ACCIDENT RFPORTING SYSTEM 1984, A REVIEW OF INFORMATION ON FATAL. TRAFFIC ACCIDENTS IN THF. U.S. IN 1984, U.S. Department of Transportation, Washingtan, D.C., in press.

2. National Highway Traffic Safety Administration, NATIONAI ACCIDENT SAMPLING SYSTEM 1983, A REPORT ON TRAFFIC ACCIDENTS AND INJURIFS, U.S. Department of Transportation, Washington, N.C., DOT HS 806 699, January 1985.

3. Wolfe, Arthur $C_{\text {. }}$ and $0^{\prime}$ Day, James, FACTBOOK ON U.S. PEDESTRIAN ACCIDENTS, Highway Safety Research Institute, University of Michigan, Report No. UM-HSRI-81-05, Ann Arbor, Michigan, sponsored by Motor Vehicle Manufacturers Association, Detroit, MI, February 1981.

4. National Highway Traffic Safety Administration, ALCOHOL AND HIGHAY SAFETY 1984: A REVIEW OF THE STATE OF KNOWLEDGF, U.S. Department of Transportation, Washington, D.C., DOT HS 806569 , February 1985.

5. U.S. Nepartment of Transportation, Transportation System Center, FATAL ACCIDFNT REPORTING SYSTEM TAPES 1975-1984, Kenda11 Square, Cambridge, sachusetts.

6. Fell, James C., TRACKING THE ALCOHOL INVOLVEMENT PROBIEM IN U.S. HIGHAY CRASHFS, National Highway Traffic Safety Administration, 27th Annual Proceedings, American Association for Automotive Medicine, San Antonio, Texas, 1983.

7. Bureau of the Census, ESTIMATES OF THE POPULATION OF THE UNJTED STATES, BY AGE, SEX AND RACE: 1980-1984, U.S. Department of Commerce, Washington, D.C., Current Population, Series P-25, No. 695, March 1985.

8. Fell, James C., ALCOHOL INVOLVEMENT IN UNITED STATES TRAFFIC ACCIDENTS: WHERE IT IS CHANGING, National Highway Traffic Safety Administration, Proceedings of Ninth International Conference on Alcohol, Drugs, and Traffic Safety (T-83), San Juan, Puer to Rico, November 1983 (also NHTSA Fell/Hazzard Technical Report MT HS 806 733). 
9. Blomberg, Richard R.; Fell, James C., and Anderson, Theodore F., A CONPARISON OF ALCOHOL INVOLVEMENT IN PEDESTRIANS AND PEDESTRIAN CASUALTIES, presented at and appears in Proceedings of 23rd Conference of the American Association FR Automotive Medicine, Louisville, KY, 1979; also published by U.S. Nepartment of Transportation, DOT HS 805521 , October 1979.

10. Reitman, Ronald, IRAM SHOP REPORTFR, Boston, Massachusetts, private communication, June 1985.

11. Hale, A.; Blomberg, R. D., and Preusser, D.F., EXPER IMENTAL FIELD TEST OF THF MONEL ICE CRFAM TRUCK ORDINANCE IN DFTROIT, Dunlop and Associates, Inc., sponsored by U.S. Department of Transportation, National Highway Traffic Safety Administration, Publication No. DOT HS 803410 , Washington, ก.C., April 1978.

12. Fell, James $C$. and Toth, Gary R., PENESTRIAN ACCIDENTS: A STATE OF THF ART 1970-80, National Highway Traffic Safety Administration, Washington, I.C., NHTSA Technical Report DOT HS 806270 , September, 1981.

13. Tsongos, Nicholas G., PEDESTRIAN ACCIDENT CHARACTERISTICS AND INJURY PATIERNS, National Highway Traffic Safety Administration, paper presented at 2nd International Congress on Traffic Medicine in Yugaslovia, Dubrovnik, Yugoslovia, 1984. 